\title{
Potential of New Isolates of Dunaliella Salina for Natural $\beta$-Carotene Production
}

\author{
Yanan Xu ${ }^{1}$, Iskander M. Ibrahim ${ }^{1,+(1)}$, Chiziezi I. Wosu ${ }^{1}$, Ami Ben-Amotz ${ }^{2}$ \\ and Patricia J. Harvey $1, *$ (D) \\ 1 Department of Life Science, Faculty of Engineering and Science, University of Greenwich, \\ Kent ME4 4TB, UK; y.xu@greenwich.ac.uk (Y.X.); ibrahii@purdue.edu (I.M.I.); \\ chiziezi.wosu@greenwich.ac.uk (C.I.W.) \\ 2 Nature Beta Technologies (NBT) Ltd., Eilat 88106, Israel; amiba@bezeqint.net \\ * Correspondence: p.j.harvey@greenwich.ac.uk; Tel.: +44-20-8331-9972 \\ + Current address: Department of Biochemistry and Purdue Center for Plant Biology, \\ Purdue University, West Lafayette, IN 47907, USA.
}

Received: 15 December 2017; Accepted: 29 January 2018; Published: 1 February 2018

\begin{abstract}
The halotolerant microalga Dunaliella salina has been widely studied for natural $\beta$-carotene production. This work shows biochemical characterization of three newly isolated Dunaliella salina strains, DF15, DF17, and DF40, compared with D. salina CCAP 19/30 and D. salina UTEX 2538 (also known as D. bardawil). Although all three new strains have been genetically characterized as Dunaliella salina strains, their ability to accumulate carotenoids and their capacity for photoprotection against high light stress are different. DF15 and UTEX 2538 reveal great potential for producing a large amount of $\beta$-carotene and maintained a high rate of photosynthesis under light of high intensity; however, DF17, DF40, and CCAP 19/30 showed increasing photoinhibition with increasing light intensity, and reduced contents of carotenoids, in particular $\beta$-carotene, suggesting that the capacity of photoprotection is dependent on the cellular content of carotenoids, in particular $\beta$-carotene. Strong positive correlations were found between the cellular content of all-trans $\beta$-carotene, 9-cis $\beta$-carotene, all-trans $\alpha$-carotene and zeaxanthin but not lutein in the $D$. salina strains. Lutein was strongly correlated with respiration in photosynthetic cells and strongly related to photosynthesis, chlorophyll and respiration, suggesting an important and not hitherto identified role for lutein in coordinated control of the cellular functions of photosynthesis and respiration in response to changes in light conditions, which is broadly conserved in Dunaliella strains. Statistical analysis based on biochemical data revealed a different grouping strategy from the genetic classification of the strains. The significance of these data for strain selection for commercial carotenoid production is discussed.
\end{abstract}

Keywords: Dunaliella salina; new isolates; characterization; light intensity; $\beta$-carotene; carotenoids; correlations; lutein; classification

\section{Introduction}

Natural carotenoids have gained increasing attention in recent years because of their health benefits compared to synthetic carotenoids [1]. These lipophilic compounds comprise a range of carotenes and xanthophylls, and their health benefits generally derive from their ability to quench oxygen radicals and absorb potential damaging visible light [2-4]. Carotenoids predominantly occur in their trans configuration but are also naturally found in their cis configuration [5]. Methods for producing synthetic carotenoids especially $\beta$-carotene and zeaxanthin are well-established [1], however synthetic carotenoids are predominantly all-trans compounds and are of questionable benefit [6]. By contrast, intake of food supplements enriched with natural $\beta$-carotene containing both cis- and trans- stereoisomers is linked with mitigation of a range of diseases including atherosclerosis, 
diabetes, psoriasis and ophthalmologic diseases [7-9]. 9-cis $\beta$-carotene is of particular nutritional and medical interest as a retinoid precursor and is associated with therapeutic effects in a number of diseases as well as possessing a good adverse effect profile [10]. This stereoisomer is difficult to synthesize chemically, it is not produced biologically by heterotrophs such as bacteria or yeasts, through fermentation, and it is present in only low amounts in fruits and vegetables [11,12]. 9-cis $\beta$-carotene, along with the 13-cis and 15-cis isomers found in food and naturally-occurring substances, may serve an important function in human physiology that cannot be replaced by synthetic $\beta$-carotene.

Microalgae are considered the richest sources of natural carotenoids, especially strains of the Chlorophyta such as Dunaliella salina, Haematococcus pluvialis, and various Chlorella species [3]. The content of lutein in marigold flowers for example is commonly reported to be $0.3 \mathrm{mg} \cdot \mathrm{g}^{-1}$, but in microalgae, the content can be over $4 \mathrm{mg} \cdot \mathrm{g}^{-1}$ [13]. Dunaliella strains are well known for being rich in lutein, zeaxanthin and $\beta$-carotene [14] and $D$. salina has been particularly widely studied as it is the richest source of natural $\beta$-carotene [15] and contains high content of the 9 -cis isomer $(\sim 50 \%$ of the total $\beta$-carotene) [11,12]. Other valuable carotenoids with potential medical value are also present in D. salina including violaxanthin, antheraxanthin, zeaxanthin, $\alpha$-carotene, and lycopene [16]. The genus Dunaliella contains a number of species and many strains which have been identified under the same species possess various carotenogenic abilities and carotenoid compositions [17].

In this study, as part of the D-Factory, an European Union (EU) funded project, three new strains of Dunaliella species, DF15, DF17, and DF40 isolated from salt ponds in Israel and Spain were characterized. The strains have been genetically identified as strains of Dunaliella salina but under different subgroups (Marine Biological Association-MBA, www.mba.ac.uk/culture-collection/). The biochemical properties of the strains were examined in this study in comparison to the known carotene hyperaccumulator, D. salina UTEX 2538, also classified as D. bardawil in some studies [4] and D. salina CCAP19/30, which has been found to be very similar to a D. tertiolecta strain and does not accumulate $\beta$-carotene under stress [18], in order to assess their potential for the commercial production of carotenoids and provide further insight into carotenoid metabolism.

\section{Materials and Methods}

\subsection{Algal Strains and Cultivation}

D. salina UTEX 2538 was obtained from the Culture Collection of Algae at The University of Texas at Austin (UTEX, Austin, TX, USA) and D. salina CCAP 19/30 was obtained from the Culture Collection of Algae and Protozoa at Scottish Marine Institute (CCAP, Scotland, UK). D-Factory strains DF15 and DF17 were isolated from a salt pond in Eilat, Israel, and DF40 was isolated from a salt pond in Monzon, Spain. The new isolates were identified as strains of or closely related to Dunaliella salina (bardawil) by The Marine Biological Association (MBA, Plymouth, Devon, UK) and are now deposited at the MBA culture collection (www.mba.ac.uk/culture-collection/). Algae were cultured in Modified Johnsons Medium [19] containing $10 \mathrm{mM} \mathrm{NaHCO}_{3}$ with the $\mathrm{pH}$ value adjusted to 7.5 with $10 \mathrm{mM}$ Tris-buffer, and $1.5 \mathrm{M} \mathrm{NaCl}$, which has been tested as the optimal salinity for cell growth of the strains. Cultures were maintained in a temperature-controlled growth chamber at $20 \pm 2{ }^{\circ} \mathrm{C}$ with illumination provided under a $12 \mathrm{~h}$ light, $12 \mathrm{~h}$ dark cycle (12/12 LD) by white light-emitting diode (LED) lights with a light intensity of $\sim 200 \mu \mathrm{mol}$ photons $\cdot \mathrm{m}^{-2} \cdot \mathrm{s}^{-1}$.

For algal cultivation, small stock cultures were grown to mid-log phase at $25^{\circ} \mathrm{C}$ in an incubator and diluted 1 in $50(v / v)$ as inoculum for larger cultures in each experiment. Erlenmeyer flasks containing $500 \mathrm{~mL}$ culture each were maintained at $25^{\circ} \mathrm{C}$ in an ALGEM Environmental Modeling Labscale Photobioreactor (Algenuity, Bedfordshire, UK) with strictly controlled conditions of light, temperature and mixing level. Under $12 / 12 \mathrm{LD}$ conditions, cell growth under a range of light intensities $\left(200,500,1000\right.$, and $\left.1500 \mu \mathrm{mol} \cdot \mathrm{m}^{-2} \cdot \mathrm{s}^{-1}\right)$ of white LED light were compared. Each growth condition was set up at least in triplicate. Cell growth was monitored automatically in the bioreactor by recording the value obtained for light scatter at $725 \mathrm{~nm}$ in optical density (OD) units. Cultures were mixed 
at $100 \mathrm{rpm}$ for $10 \mathrm{~min}$ every hour before measuring the OD. Cell concentration was determined by counting the cell number in culture broth using a haemocytometer after fixing the cells with $2 \%$ formalin. The maximum specific growth rate of all cultures was calculated to compare cell growth under different conditions.

\subsection{Microscopy Observations}

The Eclipse Ti-U inverted research microscope (Nikon, Tokyo, Japan) with a Nikon Digital Sight DS-Fi1 camera system was used to take brightfield microscopy photographs of cells of each Dunaliella strain. The objective lens used was Nikon Splan Fluor ELWD $60 \times / 0.7$ and the ocular lens was Nikon CFI $10 \times / 22$. The NIS-Elements Advanced Research Microscope Imaging Software (Nikon, Tokyo, Japan) was used to acquire the photos. Differential interference contrast (DIC) microscopy photographs were also obtained using a confocal microscope system ZEISS LSM 880 (Carl Zeiss Microscopy GmbH, Jena, Germany). The ZEISS Plan Apochromat $63 \times / 1.4$ oil DIC objective lens and the Carl Zeiss PI $10 \times / 23$ ocular lens were used. Images were acquired and analyzed through the ZEN 2.1 LSM software (Carl Zeiss Microscopy GmbH).

\subsection{Algal Biomass Analysis}

Algae grown under different light intensities were harvested during mid log phase of growth at the end of the light period. Pigments were extracted from the biomass harvested from $1 \mathrm{~mL}$ samples of the cultures using $1 \mathrm{~mL}$ of $80 \%(v / v)$ acetone. The absorbance of the acetone extract after clarification at the centrifuge was measured at $480 \mathrm{~nm}$ for total carotenoids using an ultraviolet (UV)/Vis spectrophotometer. The content of total carotenoids was calculated according to Strickland \& Parsons [20]. Chlorophyll a, b, and total chlorophyll were evaluated by measuring absorbance of the acetone extract at $664 \mathrm{~nm}$ and $647 \mathrm{~nm}$ and calculated according to Porra et al. [21].

The compositions of pigments extracted from different strains were analyzed using high performance liquid chromatography (HPLC) with diode array detection (DAD) (Agilent Technologies 1200 series, Agilent, Santa Clara, CA, USA). Carotenoid standards of all-trans $\alpha$-carotene, all-trans $\beta$-carotene and zeaxanthin were obtained from Sigma-Aldrich, Inc. (Merck KGaA, Darmstadt, Germany). Lutein and 9-cis $\beta$-carotene were obtained from Dynamic Extractions (Tredegar, UK). Carotenoids and chlorophylls were extracted from freshly harvested cells using methyl tert-butyl ether (MTBE) and Methanol (MeOH) (20:80) as extraction solvent. $15 \mathrm{~mL}$ of algal culture was centrifuged at $3000 \mathrm{~g}$ at $18{ }^{\circ} \mathrm{C}$ for $5 \mathrm{~min}$ and the pellet was extracted with $10 \mathrm{~mL}$ MTBE-MeOH (20:80) and sonicated for $20 \mathrm{~s}$. The sample was clarified by centrifugation at $3000 \mathrm{~g}$ at $18{ }^{\circ} \mathrm{C}$ for $5 \mathrm{~min}$, then $1-2 \mathrm{~mL}$ of the supernatant was filtered through $0.45 \mu \mathrm{m}$ syringe filter into amber HPLC vials. It was then analyzed using a YMC30 $250 \times 4.9 \mathrm{~mm}$ I.D S- $5 \mu$ HPLC column with DAD at $25{ }^{\circ} \mathrm{C}$, and isocratic elution with $80 \%$ methanol: $20 \%$ MTBE, flow rate of $1 \mathrm{~mL} \cdot \mathrm{min}^{-1}$, pressure of 90 bar. The quantities of 9 -cis and all-trans $\beta$-carotene, all-trans $\alpha$-carotene, lutein, and zeaxanthin in the biomass were determined from the corresponding standard curves. Glycerol, known to be regulated by salinity, was determined according to the procedures described in a Xu et al. [18].

\subsection{Oxygen Evolution and Dark Respiration}

Cells were harvested during the exponential phase and $\mathrm{NaHCO}_{3}$ was added to a final concentration of $10 \mathrm{mM} 5 \mathrm{~min}$ before the start of each measurement. The rates of net $\mathrm{O}_{2}$ evolution and dark respiration were measured as described by Brindley et al. [22] at $25^{\circ} \mathrm{C}$ using a Clark-type electrode (Hansatech Instruments Ltd, Norfolk, UK) [23]. $\mathrm{O}_{2}$ evolution was induced with $1500 \mu \mathrm{mol}$ photons $\cdot \mathrm{m}^{-2} \cdot \mathrm{s}^{-1}$ actinic light. After initial $30 \mathrm{~min}$ of dark adaption, $\mathrm{O}_{2}$ evolution was measured for $5 \mathrm{~min}$ followed by dark respiration for $20 \mathrm{~min}$. The average net rate of photosynthesis was then determined from the oxygen concentration gradient recorded over $5 \mathrm{~min}, \mathrm{dO}_{2} / \mathrm{dt}$. Dark respiration was determined by following the same procedure, except that oxygen uptake was calculated from data recorded during the last $5 \mathrm{~min}$ of the 20 min experiment. Sodium dithionite was used to calibrate the oxygen electrode. 


\subsection{Statistical Analysis}

The data generated in this study was analyzed in R (Rstudio, Boston, MA, USA). A two-way analysis of variance (ANOVA) analysis was performed to study the relationships of a series of variables measured with two factors in this work: strain and light intensity. The two-way ANOVA tests three omnibus effects: the main effect of strain or light intensity, and the interaction effect between these two factors. Correlation analysis was used to evaluate the association between each pair of the variables and the Pearson correlation method was chosen to measure the linear dependence between two variables. In correlation analysis, a correlation coefficient (the Pearson Product Moment correlation coefficient) was estimated for each pair of the variables studied. Whether or not an observed correlation is statistically significant or not was evaluated by $P$ values (significant when $P \leq 0.05$ ). Hierarchical cluster analysis is based on the strength of the correlations and the distance in the clustering dendrogram reflects the dissimilarity among these parameters. Traits examined with strong correlations are grouped as a cluster. A principle component analysis was carried out using the whole data set to reveal the relatedness between the examined traits.

\section{Results}

\subsection{Cell Growth}

The work presented here shows biochemical and biophysical characterization of the three newly isolated D. salina strains: DF15, DF17 and DF40 compared with D. tertiolecta CCAP 19/30 and D. salina (bardawil) UTEX 2538, cultured under a series of light intensities. Cultures of five Dunaliella strains: CCAP 19/30, DF15, DF17, DF40, and UTEX 2538, were each maintained under identical conditions of light of $100 \sim 200 \mu \mathrm{mol} \cdot \mathrm{m}^{-2} \cdot \mathrm{s}^{-1}$ in the incubator until stationary phase, and cells were photographed using a light microscope and a confocal microscope. The five strains differed in cell shape and cell size from each other (Figure 1a,b), and the cultures of each strain were differently colored (Figure 1c). Cells of CCAP 19/30 maintained oval shapes and a green color throughout, while the four D. salina strains gradually changed from oval to round shapes and from green to orange during cultivation. An estimation of the average cell sizes based on at least 100 cells observed under the microscope showed that DF15 has a similar cell size to UTEX $2538\left(\sim 2000 \mu \mathrm{m}^{3}\right)$; DF40 and DF17 have slightly smaller sizes ( 1200 and $1000 \mu \mathrm{m}^{3}$ respectively), and CCAP 19/30 has a significantly smaller cell size than all strains examined $\left(\sim 200 \mu \mathrm{m}^{3}\right)$.

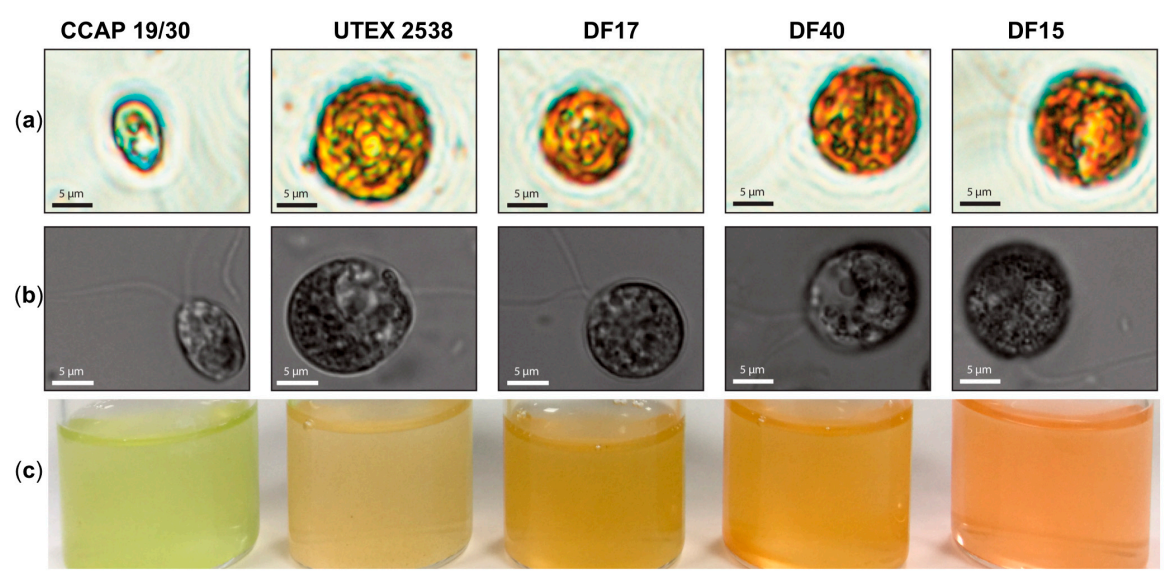

Figure 1. Microscopy observation of Dunaliella cells and photographs of stationary phase cultures of CCAP 19/30, UTEX 2538, DF17, DF40 and DF15 grown under a light intensity of 100 200 $\mu \mathrm{mol} \cdot \mathrm{m}^{-2} \cdot \mathrm{s}^{-1}$ at $20^{\circ} \mathrm{C}$. (a) Microscopy photographs taken through a light microscope (Nikon Eclipse Ti-U) with a magnification of $600 \times$; (b) Differential interference contrast (DIC) microscopy photographs taken through a confocal microscope (ZEISS LSM 880) with a magnification of $630 \times$. (c) Photographs of the cultures obtained for each Dunaliella strain grown under identical conditions. 
Growth curves for the five strains cultivated under the same conditions of different light intensities of 200, 500, 1000, and $1500 \mu \mathrm{mol} \cdot \mathrm{m}^{-2} \cdot \mathrm{s}^{-1}$ are shown in Figure 2, from which the maximum specific growth rate was calculated for each growth condition. Generally, these strains grew at a faster rate under higher light intensities. This is clearly shown for CCAP 19/30 and DF17. All strains showed the slowest growth rates under $200 \mu \mathrm{mol} \cdot \mathrm{m}^{-2} \cdot \mathrm{s}^{-1}$ light intensity. In DF15 and UTEX 2538, when increasing the light intensity from $1000 \mu \mathrm{mol} \cdot \mathrm{m}^{-2} \cdot \mathrm{s}^{-1}$ to $1500 \mu \mathrm{mol} \cdot \mathrm{m}^{-2} \cdot \mathrm{s}^{-1}$, no further improvement in cell growth rate was observed. It is likely that the optimal light intensity for fastest growth of DF15 or UTEX 2538 is around $1000 \mu \mathrm{mol} \cdot \mathrm{m}^{-2} \cdot \mathrm{s}^{-1}$, while $1500 \mu \mathrm{mol} \cdot \mathrm{m}^{-2} \cdot \mathrm{s}^{-1}$ or higher is optimal for the other three strains under the specific growth conditions used (white LED lights under $25^{\circ} \mathrm{C}$ with $10 \mathrm{~min}$ mixing at $100 \mathrm{rpm}$ every hour). DF15 had the slowest growth rate and CCAP 19/30 the fastest.

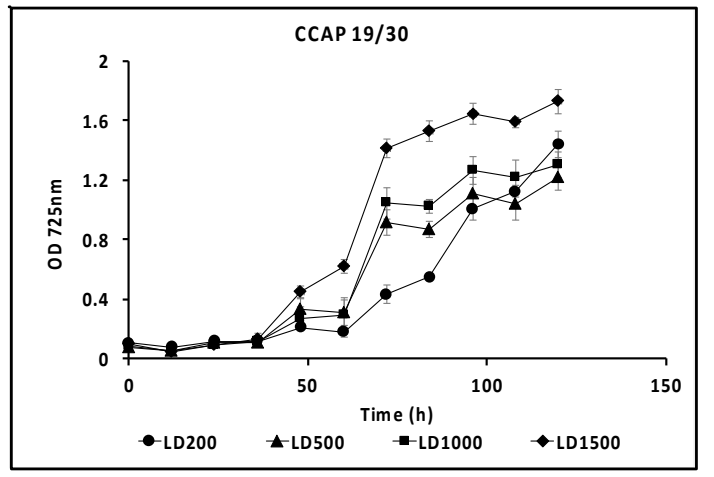

(a)

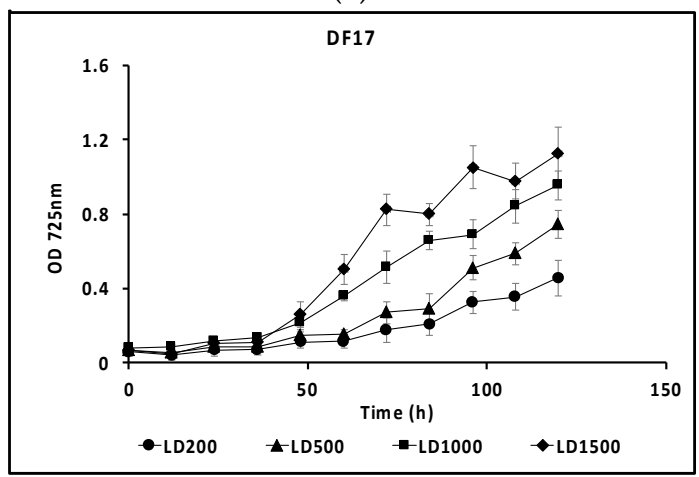

(c)

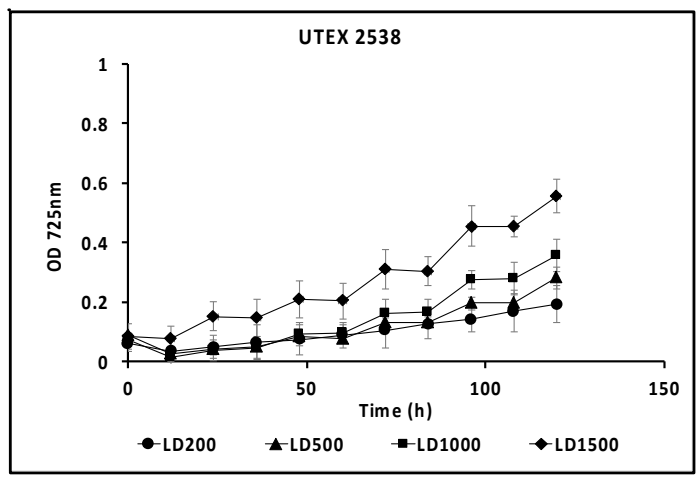

(e)

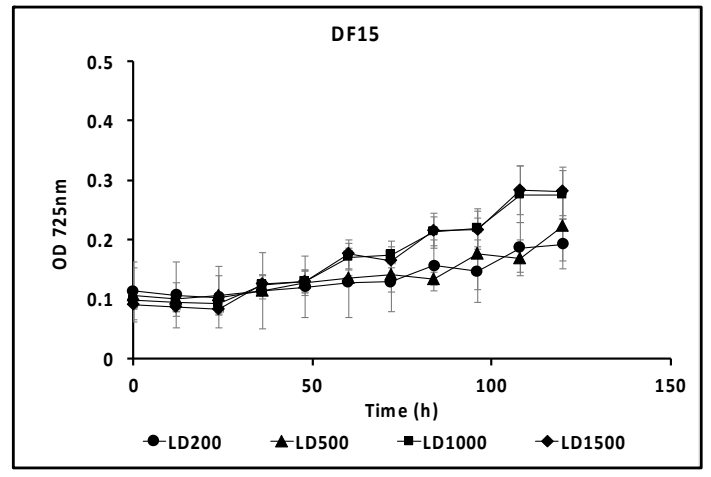

(b)

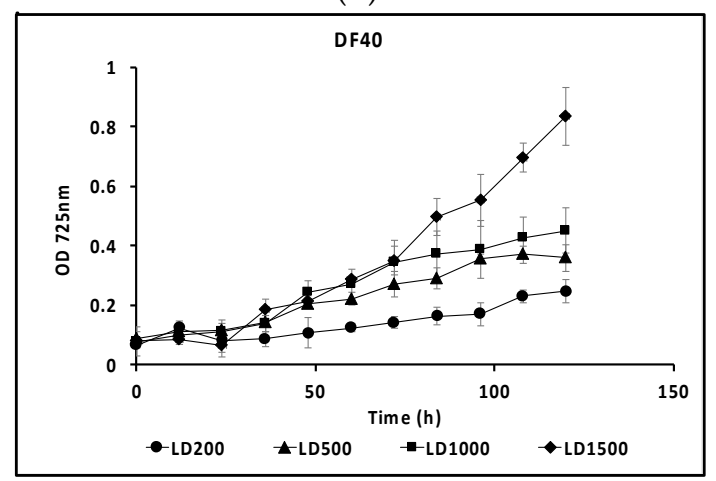

(d)

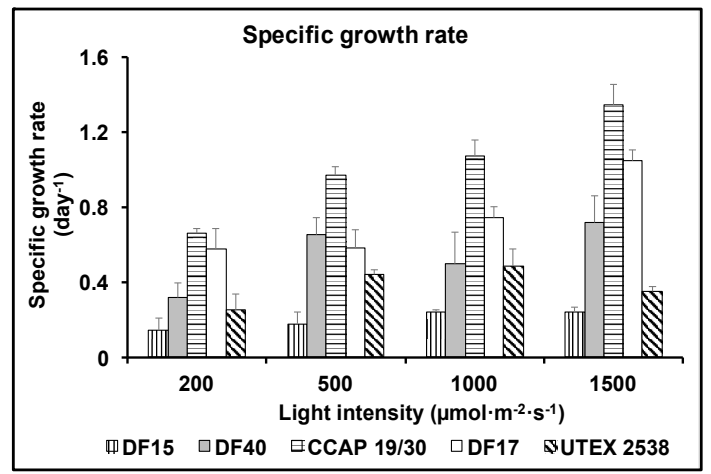

(f)

Figure 2. Growth curves for the five Dunaliella strains: (a) CCAP 19/30; (b) DF15; (c) DF17; (d) DF40; (e) UTEX 2538 each grown under four identical light intensities of 200,500, 1000 and $1500 \mu \mathrm{mol} \cdot \mathrm{m}^{-2} \cdot \mathrm{s}^{-1}$ at a light/dark cycle of $12 \mathrm{~h}$ light and $12 \mathrm{~h}$ dark (LD200, LD500, LD1000 and LD1500); (f) specific growth rates of each strain grown under the four light intensities. Each culture condition was set up in triplicate. 


\subsection{Photosynthesis and Respiration}

Figure 3a shows that as the light intensity increased, the rate of photosynthesis decreased for DF17, DF40 and CCAP 19/30, indicating that these three strains are susceptible to photoinhibition. However, DF15 and UTEX 2538 did not exhibit photoinhibition with increase in light intensity, suggesting that these two strains have a more robust photoprotection mechanism. Figure $3 \mathrm{~b}$ shows that the dark respiration rate patterns were similar for DF17, DF40, and CCAP 19/30. These three strains showed a slight decrease or no change in dark respiration rate with the increase in light intensity. DF15 and UTEX 2538 had a similar pattern to each other and their respiration rate increased slightly with increase in light intensity. From statistical analysis using two-way ANOVA, both strain difference and light intensity were significant factors affecting photosynthesis; less significant was the interaction between them. However, light intensity showed no significant impact on dark respiration, but strain played a major role in the observed differences in dark respiration (Table 1).

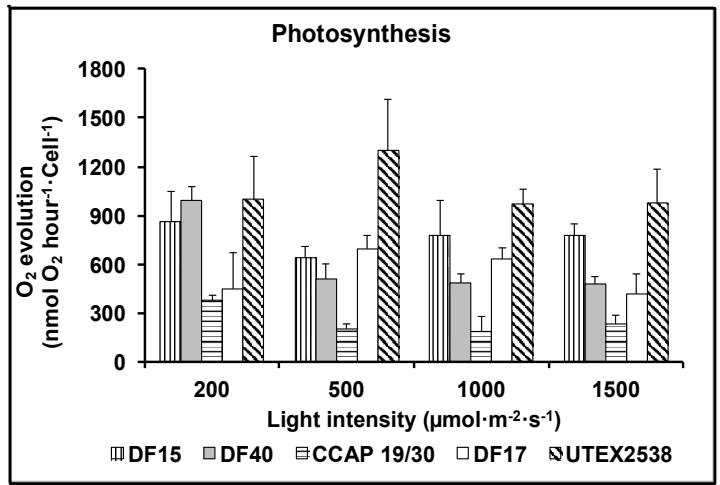

(a)

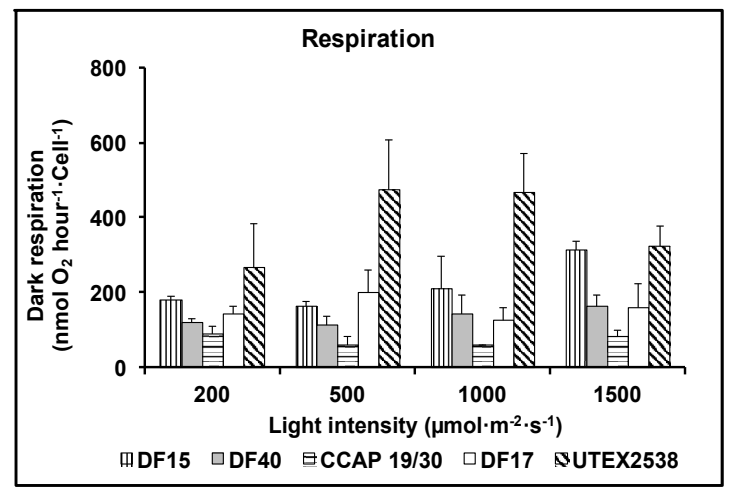

(b)

Figure 3. Photosynthesis (a) and respiration (b) of the five Dunaliella strains cultivated under four light intensities of $200,500,1000$, and $1500 \mu \mathrm{mol} \cdot \mathrm{m}^{-2} \cdot \mathrm{s}^{-1}$. Samples were taken at the mid log phase and all culture conditions were repeated at least in triplicates. 
Table 1. Two-way ANOVA analysis of the responses of all examined variables (photosynthesis, respiration, doubling time, all-trans $\beta$-carotene, 9-cis $\beta$-carotene, glycerol, lutein, zeaxanthin, all-trans $\alpha$-carotene, total carotenoids, total chlorophyll) to strain and light intensity and their interaction (Light intensity*Strain). The values of all observations were transformed by taking log function, square root function or reciprocal to fit linear models. Df: degrees of freedom; $F$ values: variation between sample means; $P$ values: significance levels and a star $\left(^{*}\right)$ indicates $P \leq 0.05$, two stars $\left(^{* *}\right) P \leq 0.01$ and three stars $\left(^{* * *}\right) P \leq 0.001$.

\begin{tabular}{|c|c|c|c|c|c|c|c|c|c|c|c|c|}
\hline \multirow[b]{2}{*}{ Response } & \multicolumn{4}{|c|}{ Light Intensity } & \multicolumn{4}{|c|}{ Strain } & \multicolumn{4}{|c|}{ Light Intensity*Strain } \\
\hline & Df & $F$ Values & $P$ Values & $\begin{array}{c}\text { Significance } \\
\text { Level }\end{array}$ & Df & $F$ Values & $P$ Values & $\begin{array}{c}\text { Significance } \\
\text { Level }\end{array}$ & Df & $F$ Values & $P$ Values & $\begin{array}{c}\text { Significance } \\
\text { Level }\end{array}$ \\
\hline Photosynthesis & 3 & 8.1825 & 0.0002 & $* * *$ & 4 & 71.2528 & $<2.2 \mathrm{e}-16$ & $* * *$ & 12 & 2.7966 & 0.0073 & $* *$ \\
\hline Respiration & 3 & 1.7925 & 0.1641 & & 4 & 52.7992 & $1.96 \mathrm{e}-15$ & $* * *$ & 12 & 2.4328 & 0.0176 & * \\
\hline Total carotenoids & 3 & 2.9403 & 0.0446 & $*$ & 4 & 693.560 & $<2.2 \mathrm{e}-16$ & $* * *$ & 12 & 7.9749 & $2.52 \mathrm{e}-07$ & $* * *$ \\
\hline Total chlorophyll & 3 & 36.529 & $1.55 \mathrm{e}-11$ & $* * *$ & 4 & 161.782 & $<2.2 \mathrm{e}-16$ & $* * *$ & 12 & 10.285 & $8.41 \mathrm{e}-09$ & $* * *$ \\
\hline All-trans $\beta$-carotene & 3 & 88.922 & $<2.2 \mathrm{e}-16$ & $* * *$ & 4 & 474.255 & $<2.2 \mathrm{e}-16$ & $* * *$ & 12 & 3.6878 & 0.0009 & $* * *$ \\
\hline 9-cis $\beta$-carotene & 3 & 28.119 & $6.02 \mathrm{e}-10$ & $* * *$ & 4 & 730.574 & $<2.2 \mathrm{e}-16$ & $* * *$ & 12 & 6.8407 & $1.67 \mathrm{e}-06$ & $* * *$ \\
\hline Lutein & 3 & 7.3679 & 0.0005 & $* * *$ & 4 & 118.762 & $<2.2 \mathrm{e}-16$ & $* * *$ & 12 & 6.4955 & $3.08 \mathrm{e}-06$ & $* * *$ \\
\hline Zeaxanthin & 3 & 35.542 & $2.31 \mathrm{e}-11$ & $* * *$ & 4 & 83.0526 & $<2.2 \mathrm{e}-16$ & $* * *$ & 12 & 5.2669 & $3.13 e-05$ & $* * *$ \\
\hline All-trans $\alpha$-carotene & 3 & 113.39 & $<2.2 \mathrm{e}-16$ & $* * *$ & 4 & 408.180 & $<2.2 \mathrm{e}-16$ & $* * *$ & 12 & 5.9987 & $7.64 \mathrm{e}-06$ & $* * *$ \\
\hline Glycerol & 3 & 2.1170 & 0.1132 & & 4 & 95.5589 & $<2.2 \mathrm{e}-16$ & $* * *$ & 12 & 5.0858 & $4.50 \mathrm{e}-05$ & $* * *$ \\
\hline
\end{tabular}

$\left({ }^{*}\right)$ indicates $P \leq 0.05,\left({ }^{* *}\right) P \leq 0.01,\left({ }^{* * *}\right) P \leq 0.001$. 


\subsection{Pigment Composition}

Cellular contents of total chlorophyll and total carotenoids were determined for the five Dunaliella strains grown under the four light intensities $\left(200,500,1000\right.$, and $\left.1500 \mu \mathrm{mol} \cdot \mathrm{m}^{-2} \cdot \mathrm{s}^{-1}\right)$ using UV/Vis spectrometry (Figure 4). Generally, the cellular content of total chlorophyll decreased while total carotenoids increased with the increase in light intensity for all five Dunaliella strains. Statistical analysis showed that strain difference significantly affected total carotenoids and total chlorophyll content, although total carotenoids and total chlorophyll content also responded significantly to light intensity (Table 1).

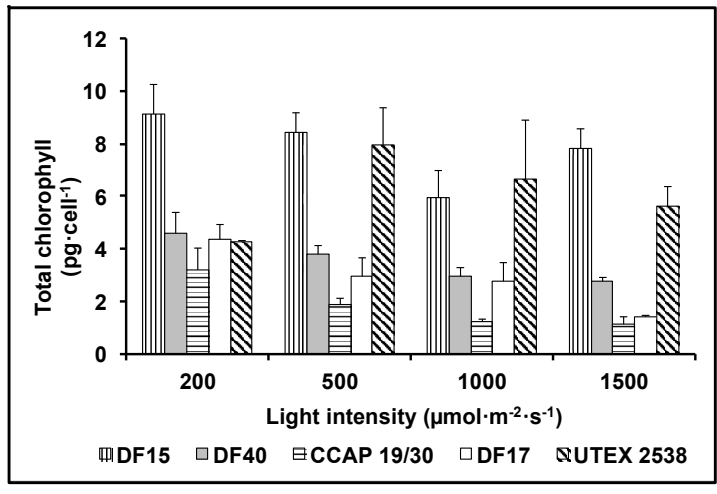

(a)

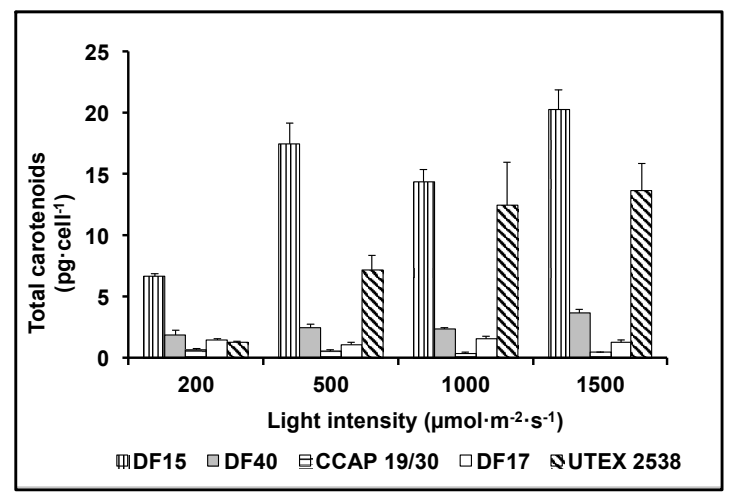

(b)

Figure 4. Cellular content of total chlorophyll (a) and total carotenoids (b) of the five Dunaliella strains grown under four light intensities of $200,500,1000$, and $1500 \mu \mathrm{mol} \cdot \mathrm{m}^{-2} \cdot \mathrm{s}^{-1}$. Samples were taken at the mid log phase and all culture conditions were repeated at least in triplicates.

HPLC-DAD was used to quantify the contents of major carotenoids, namely lutein, zeaxanthin, all-trans $\beta$-carotene, 9-cis $\beta$-carotene, and all-trans $\alpha$-carotene, in each strain acclimated in response to four light intensities, to understand the effect of light in carotenoid metabolism. Figure 5 shows HPLC chromatograms of the pigment extracts from the five Dunaliella strains grown under the light intensity of $1500 \mu \mathrm{mol} \cdot \mathrm{m}^{-2} \cdot \mathrm{s}^{-1}$. It is clear that CCAP $19 / 30$ does not accumulate $\beta$-carotene even under high light intensity. DF15, DF40 and UTEX 2538 have a similar pigment profile and $\beta$-carotene dominates the carotenoid composition. DF17 produced a higher relative amount of zeaxanthin under high light stress compared with the other strains, indicating the important role of zeaxanthin in DF17 for photoprotection.

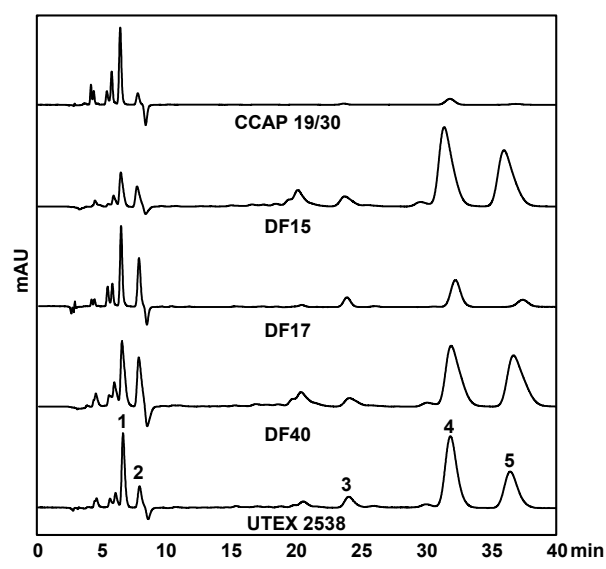

Figure 5. HPLC chromatograms of MTBE/ethanol extracts of the five Dunaliella strains cultivated under $1500 \mu \mathrm{mol} \cdot \mathrm{m}^{-2} \cdot \mathrm{s}^{-1}$. The major peaks shown are: (1) lutein, (2) zeaxanthin, (3) all-trans $\alpha$-carotene, (4) all-trans $\beta$-carotene and (5) 9-cis $\beta$-carotene. 
The major difference between the strains was their ability to accumulate $\beta$-carotene. As shown in Figure $6 \mathrm{a}, \mathrm{b}$, the contents of all-trans and 9 -cis $\beta$-carotene increased with increasing light intensity in all five strains apart from UTEX 2538, which produced the highest cellular amount of all-trans $\left(5.6 \pm 1.8 \mathrm{pg} \cdot \mathrm{cell}^{-1}\right)$ or 9 -cis $\beta$-carotene $\left(5.3 \pm 1.5 \mathrm{pg} \cdot \mathrm{cell}^{-1}\right)$ under $1000 \mu \mathrm{mol} \cdot \mathrm{m}^{-2} \cdot \mathrm{s}^{-1}$. Under the highest light intensity studied $\left(1500 \mu \mathrm{mol} \cdot \mathrm{m}^{-2} \cdot \mathrm{s}^{-1}\right)$, the cellular contents of all-trans $\beta$-carotene and 9-cis $\beta$-carotene were $9.0 \pm 0.7$ and $5.9 \pm 0.6 \mathrm{pg} \cdot \mathrm{cell}^{-1}$ in DF15; $1.1 \pm 0.5$ and $0.8 \pm 0.4 \mathrm{pg} \cdot$ cell $^{-1}$ in DF40; and $0.6 \pm 0.0$ and $0.1 \pm 0.0 \mathrm{pg} \cdot \mathrm{cell}^{-1}$ in DF17. In CCAP 19/30, the highest all-trans $\beta$-carotene content $\left(0.3 \pm 0.0 \mathrm{pg} \cdot \mathrm{cell}^{-1}\right)$ was obtained at $1000 \mu \mathrm{mol} \cdot \mathrm{m}^{-2} \cdot \mathrm{s}^{-1}$, and only a very small amount of 9-cis $\beta$-carotene was detected at all light intensities $\left(\sim 0.01 \mathrm{pg} \cdot\right.$ cell $\left.^{-1}\right)$. All five strains achieved the highest all-trans $\beta$-carotene productivity at $1500 \mu \mathrm{mol} \cdot \mathrm{m}^{-2} \cdot \mathrm{s}^{-1}(3.2 \pm 0.0,3.5 \pm 0.0,1.3 \pm 0.0$, $2.6 \pm 0.0$ and $2.9 \pm 0.0 \mathrm{mg} \cdot \mathrm{L}^{-1} \cdot \mathrm{day}^{-1}$ for CCAP 19/30, DF15, DF17, DF40 and UTEX 2538 respectively), and also the highest 9 -cis $\beta$-carotene productivity at $1500 \mu \mathrm{mol} \cdot \mathrm{m}^{-2} \cdot \mathrm{s}^{-1}$ except that UTEX 2538 has the highest yield of 9 -cis $\beta$-carotene at $1000 \mu \mathrm{mol} \cdot \mathrm{m}^{-2} \cdot \mathrm{s}^{-1}(0.2 \pm 0.0,2.3 \pm 0.0,0.2 \pm 0.0,2.0 \pm 0.0$ and $2.2 \pm 0.0 \mathrm{mg} \cdot \mathrm{L}^{-1} \cdot$ day $^{-1}$ for CCAP 19/30, DF15, DF17, DF40 and UTEX 2538 respectively). From the two-way ANOVA analysis, the cellular contents of all-trans or 9-cis $\beta$-carotene were found to vary significantly among strains and under different light intensities (Table 1). CCAP 19/30, DF17 and DF40 had similar responses to increasing light with a mild $\beta$-carotene accumulation, while DF15 and UTEX 2538 significantly increased $\beta$-carotene content with increasing light (Figure 6a,b). DF15 and UTEX 2538 have significantly higher cellular contents of all-trans- or 9-cis $\beta$-carotene than the other three strains and DF15 contains a higher cellular content of $\beta$-carotene than UTEX 2538 under most of the light conditions. UTEX 2538, already known to be a massive carotene-accumulating strain [4], had faster growth rates than DF15 under all light intensities examined, as shown in Figure 2f. On the other hand, DF15 accumulated a high carotene content even under the lowest light intensity tested here. In Dunaliella, variation in $\beta$-carotene content has been reported to correlate with the integral irradiance received during a division cycle and to be a specific mechanism of photoprotection [24], which may explain why DF15 has a higher cellular content of $\beta$-carotene than UTEX 2538. DF15 has the advantage of accumulating a large amount of $\beta$-carotene even without light stress (Figure 6), and also highest productivity of both all-trans and 9-cis $\beta$-carotene under light stress, therefore has great potential for the commercial production of $\beta$-carotene with less light energy input required.

The cellular content of lutein in the five Dunaliella strains grown under various light intensities is shown in Figure 6c. All strains accumulated considerably different amounts of lutein and the response to increasing light intensities varied among different strains. Lutein increased with light intensity from $200 \mu \mathrm{mol} \cdot \mathrm{m}^{-2} \cdot \mathrm{s}^{-1}$ to $1000 \mu \mathrm{mol} \cdot \mathrm{m}^{-2} \cdot \mathrm{s}^{-1}$ and then decreased when light increased to $1500 \mu \mathrm{mol} \cdot \mathrm{m}^{-2} \cdot \mathrm{s}^{-1}$ in UTEX 2538. In DF15, lutein content did not change with light intensity from $200 \mu \mathrm{mol} \cdot \mathrm{m}^{-2} \cdot \mathrm{s}^{-1}$ to $1000 \mu \mathrm{mol} \cdot \mathrm{m}^{-2} \cdot \mathrm{s}^{-1}$ and only increased from 1000 to $1500 \mu \mathrm{mol} \cdot \mathrm{m}^{-2} \cdot \mathrm{s}^{-1}$. Both DF15 and UTEX 2538 accumulated significantly larger amounts of lutein under high light compared with the other strains. DF17 had the highest lutein content at $1000 \mu \mathrm{mol} \cdot \mathrm{m}^{-2} \cdot \mathrm{s}^{-1}$, and the lowest at $1500 \mu \mathrm{mol} \cdot \mathrm{m}^{-2} \cdot \mathrm{s}^{-1}$. Two-way ANOVA shows the cellular content of lutein is significantly affected by both the strain and light intensity.

Figure 6d shows that zeaxanthin content in all strains increased with light intensity. DF15 accumulated the highest amount of zeaxanthin, followed by DF17, UTEX 2538, DF40 and CCAP 19/30 accumulated the lowest amount. Two-way ANOVA analysis (Table 1) shows that the factors of strain and light intensity determined the accumulation of zeaxanthin. Zeaxanthin accumulation was significantly different among strains and at different light intensities. Among the different strains, DF17 and UTEX 2538 had similar responses in terms of zeaxanthin accumulation.

The cellular content of all-trans $\alpha$-carotene of the five strains grown under different light intensities is shown in Figure 6e and the cellular content of glycerol is shown in Figure 6f. The content of all-trans $\alpha$-carotene in DF15 or UTEX 2538 was much higher than that in the other three Strains. $\alpha$-carotene is the precursor of lutein but surprisingly $\alpha$-carotene did not respond to light stress in the same way as lutein. All-trans $\alpha$-carotene increased with the light intensity in all strains examined, and its response 
to increasing light intensity was very similar to the pattern of accumulation obtained for all-trans and 9-cis $\beta$-carotene.

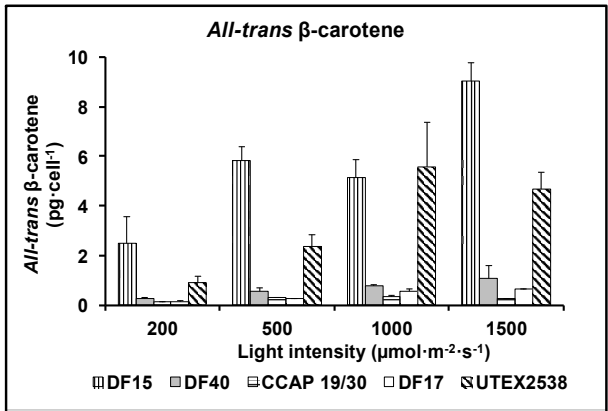

(a)

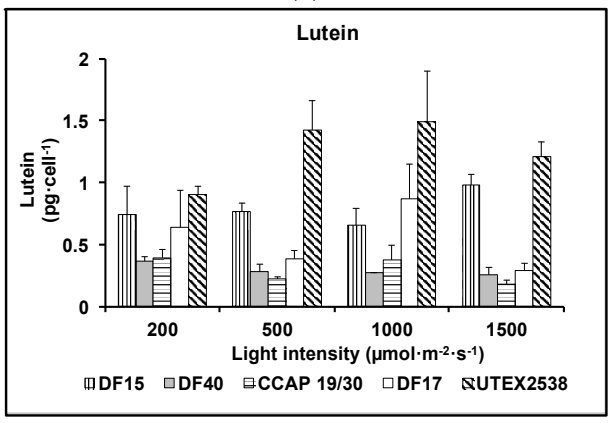

(c)

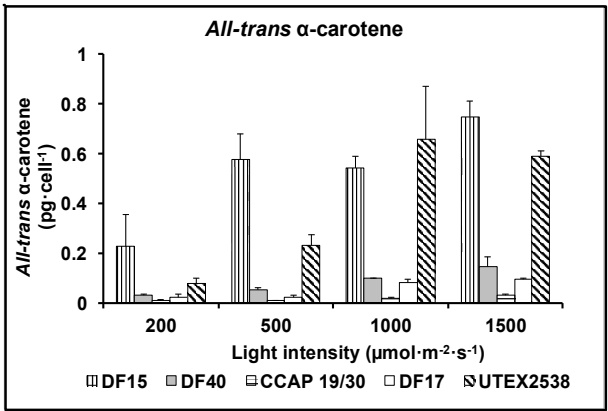

(e)

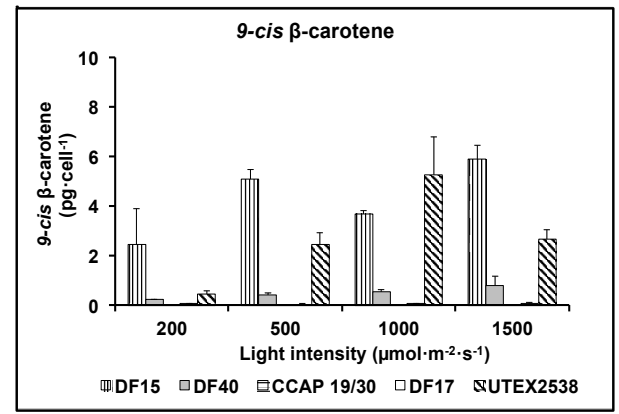

(b)

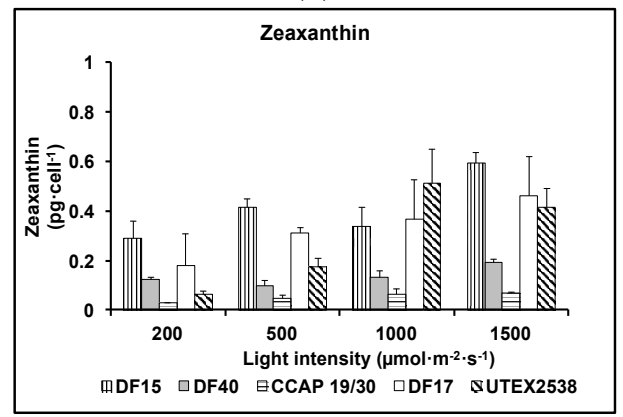

(d)

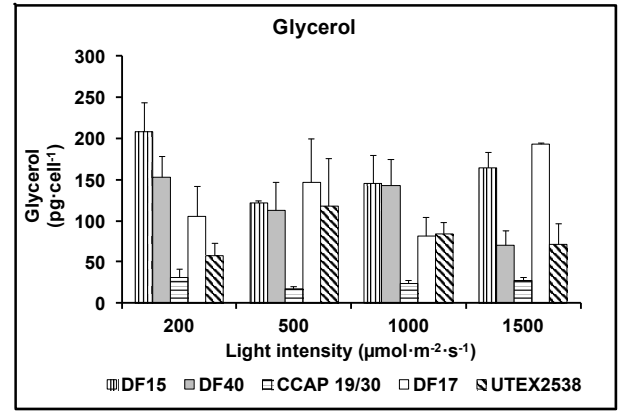

(f)

Figure 6. Cellular contents of (a) all-trans $\beta$-carotene, (b) 9-cis $\beta$-carotene, (c) lutein, (d) zeaxanthin, (e) all-trans $\alpha$-carotene and (f) glycerol in the five Dunaliella strains cultivated under four light intensities of $200,500,1000$, and $1500 \mu \mathrm{mol} \cdot \mathrm{m}^{-2} \cdot \mathrm{s}^{-1}$. Samples were taken at the mid log phase and all culture conditions were repeated at least in triplicate.

\subsection{Statistical Analysis}

Whilst the accumulated data permit elucidation of strain differences for carotenoid production, they also provided the opportunity to explore the use of statistical analysis to provide new insights into carotenoid metabolism coupled to the interdependent metabolic functions of photosynthesis and respiration. This was possible with the large set of data generated across five strains and four light intensities combined with tools of ANOVA analysis, correlation analysis, and principal component analysis used in this study. With the quantitative data obtained for the five Dunaliella strains, statistical analysis was used as a tool in order to assess the strength of the correlations among the carotenoids and other cell growth parameters and examine the differences among the five strains. A correlation and clustering analysis was performed on the growth, photosynthesis and pigment data presented, to all five strains grown under four light conditions. The analysis was performed for each strain using all variables examined in this study (all-trans $\beta$-carotene, 9-cis $\beta$-carotene, glycerol, lutein, zeaxanthin, all-trans $\alpha$-carotene, photosynthesis, respiration, total carotenoids, total chlorophyll, and specific 
growth rate). Among them, glycerol is known to maintain osmotic balance in Dunaliella strains and as expected, the cellular content of glycerol would not respond to changes in light intensity, as shown in Figure 6f. Glycerol content therefore was used to index the analysis.

The clustering dendrogram of the examined traits for each strain is shown in Figure 7 and depicts graphically several features of note amongst the strains. First, it shows that the individual carotenoids of all-trans $\beta$-carotene, 9-cis $\beta$-carotene, zeaxanthin and all-trans $\alpha$-carotene in the four $D$. salina strains are strongly correlated with each other but significantly not with lutein, except in CCAP 19/30. From this, it is clear that there is greater similarity between the four $D$. salina strains (DF15, DF17, DF40, and UTEX 2538) than with the CCAP19/30 strain. Second, the correlation analysis shows that accumulation of carotenoids is positively correlated with photosynthesis over all light intensities for the D. salina strains (also shown in Figure 8), signifying a role for carotenoids in photoprotection. Third, lutein is not correlated closely with the other carotenoids, but correlates more strongly with photosynthesis and respiration. This result suggests an important and not hitherto identified role for lutein in coordinated control of the cellular functions of photosynthesis and respiration in response to changes in light conditions, which is moreover broadly conserved in Dunaliella strains. Glycerol, which was not expected to change with light intensity, is weakly correlation with the different carotenoids in the Dunaliella strains as anticipated, but also correlates more closely with either photosynthesis or respiration.

A principle component analysis was performed with all strains growing at all tested conditions as shown in Figure 8. The examined 11 traits can be roughly grouped into four groups as shown in the graph, where all-trans $\beta$-carotene, all-trans $\alpha$-carotene, 9-cis $\beta$-carotene and zeaxanthin were clustered closely, lutein, respiration and total chlorophyll were found in a second cluster, glycerol and photosynthesis were closely correlated, and the specific growth rate stands separately. The formation of two separate clusters of the carotenoids indicates two functionally distinct mechanisms for coordinated adaptation to changes in light conditions, broadly conserved between DF15, DF40, CCAP 19/30, DF17 and UTEX 2538. More importantly, it shows that DF17 and DF40 performed similarly under the tested environmental conditions; that DF15 is closely related to UTEX 2538, and that CCAP 19/30 is different compared to all the other strains.

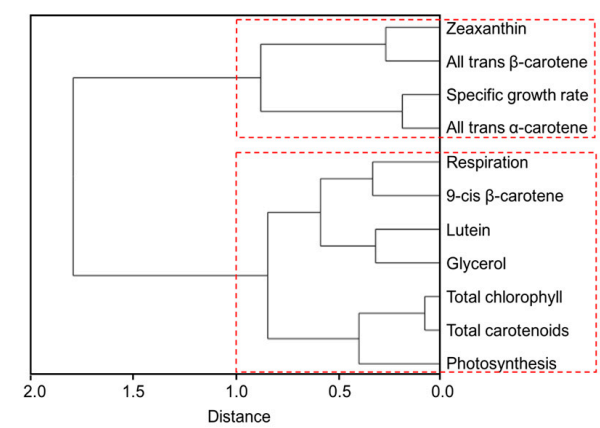

(a) CCAP $19 / 30$

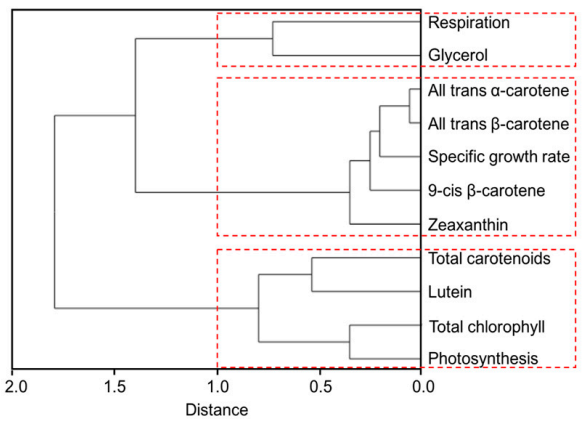

(c) DF17

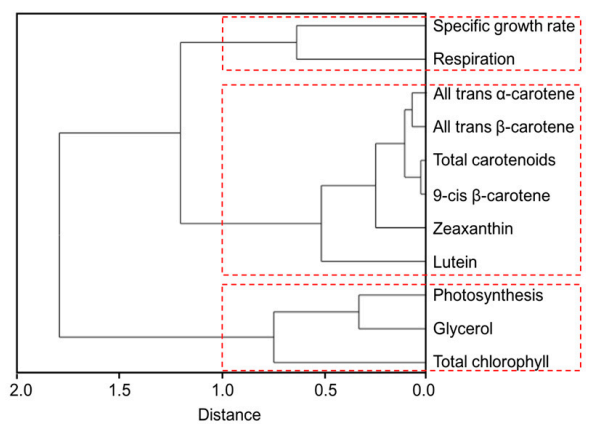

(b) DF15

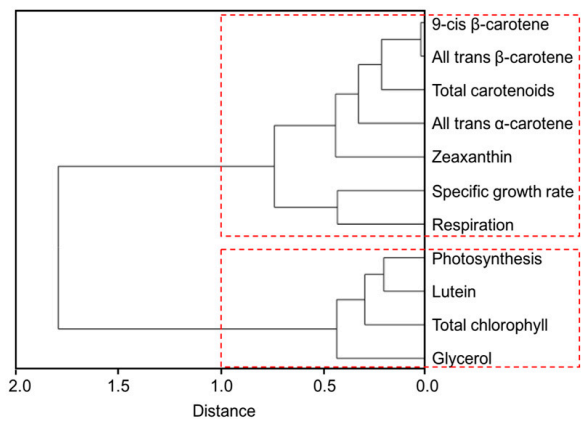

(d) DF40

Figure 7. Cont. 


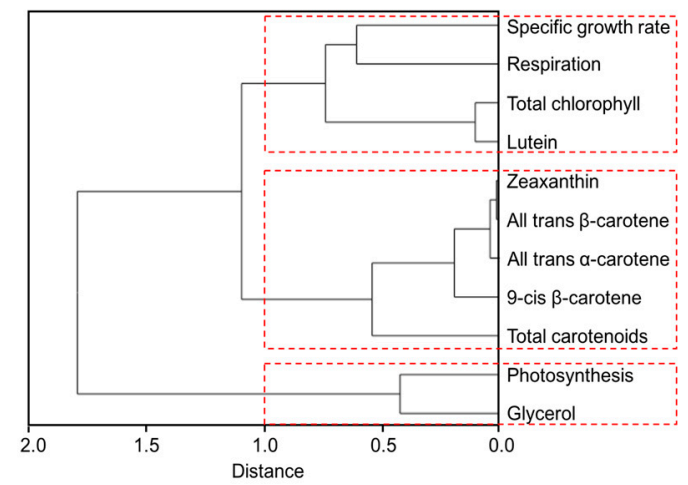

(e) UTEX 2538

Figure 7. Cluster dendrograms of all-trans $\beta$-carotene, 9-cis $\beta$-carotene, glycerol, lutein, zeaxanthin, all-trans $\alpha$-carotene, photosynthesis, respiration, total carotenoids, and total chlorophyll for all five Dunaliella strains cultivated at four light intensities. (a) CCAP 19/30; (b) DF15; (c) DF17; (d) DF40 and (e) UTEX 2538.

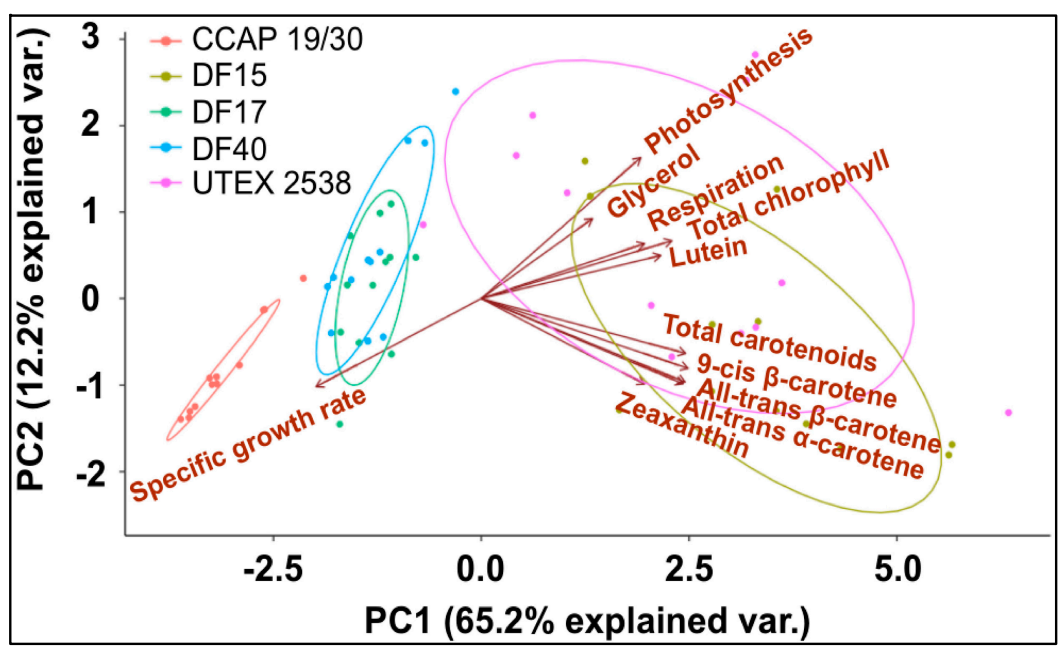

Figure 8. Principle component analysis of 11 traits (all-trans $\beta$-carotene, 9-cis $\beta$-carotene, glycerol, lutein, zeaxanthin, all-trans $\alpha$-carotene, photosynthesis, respiration, total carotenoids, total chlorophyll, and specific growth rate) for all five Dunaliella strains cultivated at four light intensities.

\section{Discussion}

In photosynthesis, light energy absorbed by the chlorophyll- and carotenoid-binding complexes of photosystem II is transferred to reaction centers to drive photochemistry. Excess light energy will cause light-induced damage of photosynthetic apparatus or photo-oxidative damage. Photosynthetic organisms have evolved a robust repair mechanism to replace the photodamaged photosystems; however, when the rate of photodamage exceeds the repair cycle, photosynthetic efficiency will be impaired [25]. Based on this study, it is apparent that CCAP 19/30, DF17 and DF40 are susceptible to photoinhibition, while photosynthetic efficiency of DF15 and UTEX 2538 was not affected by high light and was maintained high over all light intensities studied, suggesting they have developed better photoprotective mechanisms against light stress. In [18], CCAP 19/30 was shown to increase the intracellular glycerol content with increasing light intensity above $500 \mu \mathrm{mol}$ photons $\mathrm{m}^{-2} \cdot \mathrm{s}^{-1}$, but not carotenoids, as is also shown here (see Figure $6 \mathrm{f}$ ). Glycerol was proposed to have multiple functions to protect and maintain growth of CCAP 19/30 cells not only in conditions of high salinity but also under high light intensities by stabilizing the photosynthetic apparatus for maximum performance, a role normally attributed to carotenoids [18]. In the present work, all cultures were grown at the same 
salinity, and the statistical analysis for all strains examined together showed no significant changes in glycerol with light intensity. Nevertheless, it is possible that the findings reported in [18] refer more widely to all strains when compared under constant salinity.

Carotenoids are variously involved in harvesting light for photosynthesis as well as preventing photoinhibition under high light stress. Exposure to white light is associated with generation of reactive oxygen species (ROS), which have been shown to replace light in the induction of hyper-accumulation of carotenoids [26]. $\beta$-carotene is also associated with photoprotection and most of the beneficial effects of $\beta$-carotene is attributed to its ability to prevent oxidation processes by quenching singlet oxygen $\left({ }^{1} \mathrm{O}_{2}{ }^{*}\right)$ once formed or terminating free radical chain reactions as a result of the presence of the polyene chain, with 9-cis $\beta$-carotene being a better scavenger of free radicals than all-trans $\beta$-carotene [27]. DF15 and UTEX 2538, which showed no evidence of photoinhibition with increase in light intensity, also accumulated large amounts of carotenoids, especially $\beta$-carotene, compared to the other strains.

The fact that DF15 and UTEX 2538 accumulated very large amounts of $\beta$-carotene over all light intensities is noteworthy. The accumulation of $\beta$-carotene in $D$. salina when exposed to high light mainly occurs in the $\beta$-carotene plastoglobuli, while the thylakoidal $\beta$-carotene content remains relatively unchanged $[28,29]$. These plastoglobuli have also been shown to contain many enzymes found in the eyespot of other flagellate algae [30,31]. However, most of the proteins that are required for the eyespot function are no longer found in Dunaliella and no eyespot structural elements could be found in Dunaliella [32]. This suggests that the plastoglobuli were once components of a functional eyespot of Dunaliella. The $\beta$-carotene in the eyespot probably played a crucial role in perception of light, but once it lost its function, the non-functional eyespot acted as a $\beta$-carotene storage compartment. It is possible therefore that both DF15 and UTEX 2538 accumulated very large amounts of $\beta$-carotene in a vestigial eye-spot.

Zeaxanthin is linked to energy dissipation when excess light is absorbed via the xanthophyll cycle $[33,34]$. Zeaxanthin receives excess excitation energy from excited-state singlet chlorophyll $\left({ }^{1} \mathrm{Chl}^{*}\right)$ and dissipates it harmlessly and rapidly as heat in a process that is commonly assessed as non-photochemical quenching (NPQ) of chlorophyll fluorescence $[33,34]$. The carotenoids participating in this cycle are the only carotenoids present in the photosynthetic membrane that undergo very rapid, light-triggered concentration changes. High light induces de-epoxidation of violaxanthin and converts it into zeaxanthin, leading to its accumulation. This process is reversed in low light conditions. The accumulation of zeaxanthin in Dunaliella has been shown to parallel the accumulation of photodamaged Photosystem II (PSII) centers in the chloroplast thylakoids and decays with chloroplast recovery from photoinhibition [35]. In the present work, the increase in zeaxanthin content in high light, therefore shows that these strains have an efficient photoprotective mechanism also based on the xanthophyll cycle.

Statistical analysis tools used here have been able to reveal the correlative relationships between different carotenoids (lutein, zeaxanthin, all-trans and 9-cis $\beta$-carotene and $\alpha$-carotene) and the relationships between carotenoids and photosynthesis and respiration. In particular, they have identified a strong positive correlation of lutein with photosynthesis and respiration (Figures 7 and 8). In humans, lutein influences brain function through a variety of mechanisms that are not well understood, but its accumulation in brain mitochondria has been proposed to protect these organelles from oxidative damage [36]. Lutein also specifically accumulates in the retina of the eye and has been linked with protection against mitochondrial stress and with mitochondrial biogenesis [37]. In plants there is a close interdependence between respiration and photosynthesis for the flow of adenosine triphosphate (ATP), nicotinamide adenine dinucleotide phosphate $(\mathrm{NAD}(\mathrm{P}) \mathrm{H})$ and carbon skeletons such that excess photosynthetic reducing equivalents formed by photosynthesis in light can be removed in mitochondrial respiration to reduce the tendency for reactive oxygen species (ROS) accumulation and photoinhibition [38] and thereby regulate the $\mathrm{NAD}(\mathrm{P}) \mathrm{H}$ : oxygen ratio to avoid cell death [39]. The clustering of lutein, photosynthesis, chlorophyll and respiration reported here attests to the strong 
interdependence between respiration and photosynthesis to regulate the redox state of the cell [38], and in Dunaliella both are linked to lutein accumulation.

Figure 9 shows the pathway for the synthesis of key carotenoids in this study. Significantly the data presented here show that $\alpha$-carotene is linearly correlated with $\beta$-carotene but not lutein, although $\alpha$-carotene is the precursor of lutein. Lutein, the most abundant xanthophyll in higher plants, is found in the light harvesting complexes in higher plants and also protects against photodamage. Its most important function is thought to be in quenching triplet chlorophyll $\left({ }^{3} \mathrm{Chl}^{*}\right)$ to prevent energy transfer to molecular oxygen and consequent formation of singlet oxygen $\left({ }^{1} \mathrm{O}_{2}{ }^{*}\right)$ [34], but it also quenches excited ${ }^{1} \mathrm{Chl}^{*}$ (NPQ) to prevent the formation of reactive oxygen species (ROS) under high light [40]. It also contributes to light harvesting, by transferring excitation energy to chlorophyll, and has a structural role associated with the antenna system [34], consequently the changes in antenna size due to photodamage under high light may also affect lutein content. Lutein in D. salina has been previously reported as a growth-coupled primary metabolite with a strong correlation with chlorophyll synthesis, but interestingly, not with light [41]. The finding in this study points to additional interactions involved in the synthesis of lutein, which are linked specifically to chlorophyll synthesis. Moreover, the positive correlation between $\beta$-carotene and zeaxanthin may suggest a proportional partitioning of $\beta$-carotene into the xanthophyll cycle and the $\beta$-carotene plastoglobuli, which is consistent with the idea that two complete pathways for $\beta$-carotene biosynthesis exist in D. barwawil, one in the chloroplast membranes for the biosynthesis of $\beta$-carotene and one in the plastoglobuli for the accumulation of $\beta$-carotene [29]. It is possible to conclude that $D$. salina strains have evolved coordinated universal photoprotection mechanisms for the maintenance of high efficiency under high light stress by accumulating carotenoids, in particular $\beta$-carotene. However, the effectiveness of these mechanisms varies greatly between strains and therefore the potential for $\beta$-carotene production varies among strains.

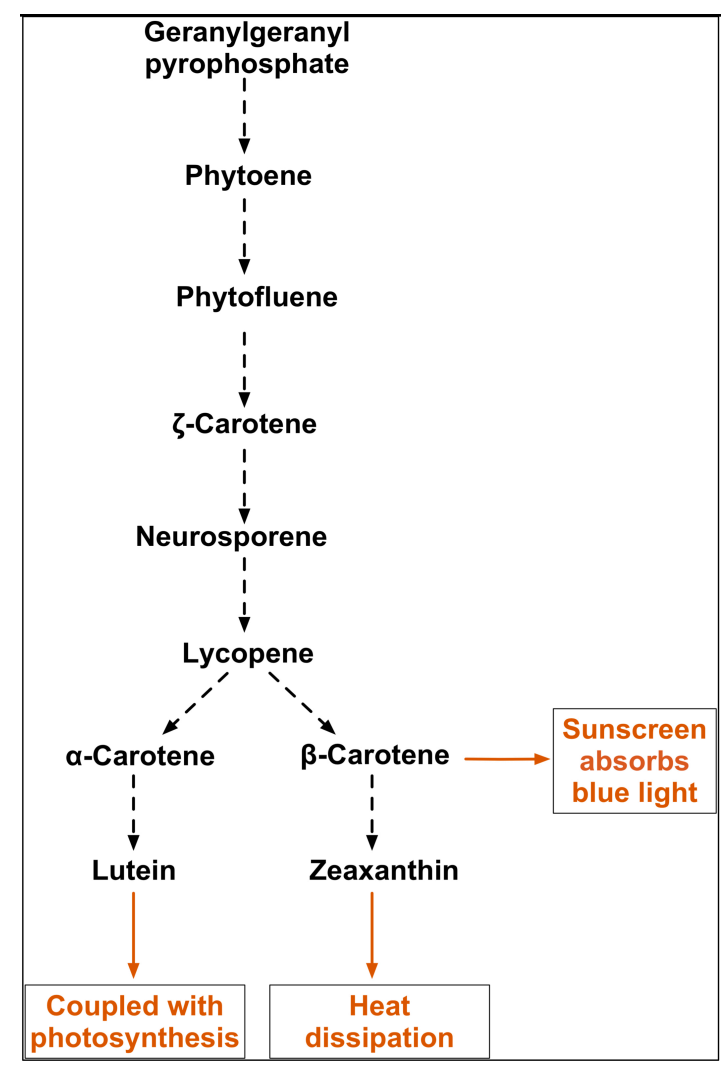

Figure 9. Carotenoids pathway showing synthesis of lutein, $\beta$-carotene, $\alpha$-carotene, and zeaxanthin from phytoene in D. salina and possible functions of the major carotenoids (Adapted from [42,43]). 
Finally, it is noteworthy that the statistical analysis based on the data obtained from the biochemical characterization suggests a grouping of the five strains into three different groups: (1) DF15 and UTEX 2538; (2) DF17 and DF40; and (3) CCAP 19/30 as shown in Figure 8. However, genetic classification using the approaches of bar coding shows a higher similarity between DF40 and UTEX 2538, and therefore groups the five strains into four different groups: (1) DF40 and UTEX 2538, (2) DF17, (3) DF15, and (4) CCAP 19/30 as shown in the phylogenetic tree provided by Dr. Declan Schroeder at The Marine Biological Association, UK [44] (Figure 10). This indicates the complicity of strain classification in Dunaliella by using a single classification method, and the importance of strain selection for the commercial production of Dunaliella biomass and natural $\beta$-carotene.

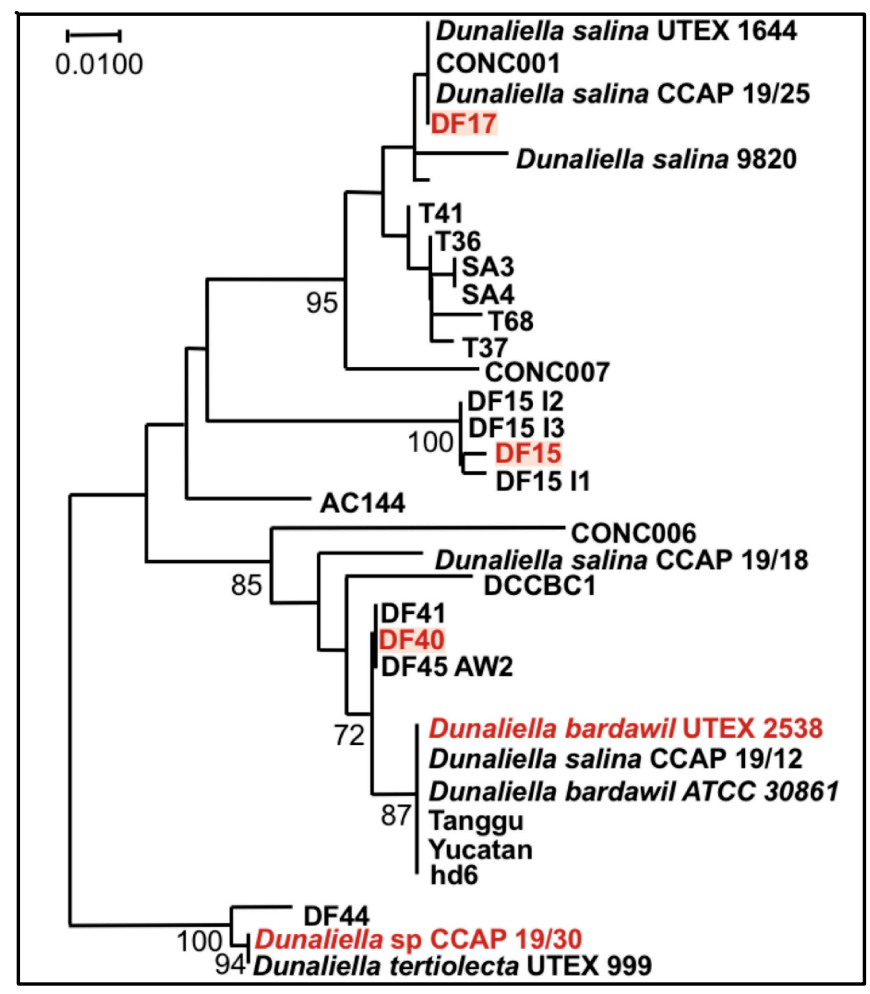

Figure 10. Phylogenetic tree showing the location of the three newly isolated Dunaliella strains (DF15, DF17, and DF40) compared to CCAP 19/30 and UTEX 2538 used in this study [44].

\section{Conclusions}

This study shows how strain difference plays a significant role in the accumulation of carotenoids in D. salina. Carotenoid content increased with the increase of light intensity and contributed to photoprotection against photodamage. Cellular contents of all-trans $\beta$-carotene, 9-cis $\beta$-carotene, all-trans $\alpha$-carotene and zeaxanthin, but not lutein, were closely correlated with each other, signifying synthesis of these carotenes and zeaxanthin along a metabolic pathway that is under common control. Significantly a strong correlation between lutein and respiration in photosynthetic cells was identified; there was also a strong relationship between lutein, photosynthesis, chlorophyll, and respiration. Among the three newly isolated D. salina strains, DF15 produced a significantly higher ( $>5$-fold) content of $\beta$-carotene over different light intensities compared to DF17 or DF40, despite the fact that they are all strains of $D$. salina. Physiological study on the biochemical performance of the new isolated strains shows a different grouping strategy to that obtained from genetic classification. The data demonstrate the importance of strain selection from a number of Dunaliella strains based on their biochemical performance for the commercial production of $\beta$-carotene. 
Acknowledgments: This research was supported by the grant EU KBBE.2013.3.2-02 programme (D-Factory: 368 613870). The authors would like to express their sincere gratitude to Dr. Declan Schroeder at MBA for invaluable discussion.

Author Contributions: Y.X., I.M.I., A.B.-A. and P.J.H. conceived and designed the experiments; Y.X., I.M.I. and C.I.W. performed the experiments; Y.X. and I.M.I. analyzed the data; P.J.H. contributed reagents/materials/analysis tools; Y.X. I.I. and P.J.H. wrote the paper.

Conflicts of Interest: The authors declare no conflict of interest. The founding sponsors had no role in the design of the study; in the collection, analyses, or interpretation of data; in the writing of the manuscript, and in the decision to publish the results.

\section{References}

1. Gong, M.; Bassi, A. Carotenoids from microalgae: A review of recent developments. Biotechnol. Adv. 2016, 34, 1396-1412. [CrossRef] [PubMed]

2. Takaichi, S. Carotenoids in algae: Distributions, biosyntheses and functions. Mar. Drugs 2011, 9, 1101-1118. [CrossRef] [PubMed]

3. Zhang, J.; Sun, Z.; Sun, P.; Chen, T.; Chen, F. Microalgal carotenoids: Beneficial effects and potential in human health. Food Funct. 2014, 5, 413-425. [CrossRef] [PubMed]

4. Ben-Amotz, A.; Shaish, A.; Avron, M. Mode of action of the massively accumulated $\beta$-Carotene of Dunaliella bardawil in protecting the alga against damage by excess irradiation. Plant Physiol. 1989, 91, 1040-1043. [CrossRef] [PubMed]

5. Schieber, A.; Carle, R. Occurrence of carotenoid cis-isomers in food: Technological, analytical, and nutritional implications. Trends Food Sci. Technol. 2005, 16, 416-422. [CrossRef]

6. Levy, Y.; Zaltsberg, H.; Ben-Amotz, A.; Kanter, Y.; Aviram, M. Dietary supplementation of a natural isomer mixture of beta-carotene inhibits oxidation of LDL derived from patients with diabetes mellitus. Ann. Nutr. Metab. 2000, 44, 54-60. [CrossRef] [PubMed]

7. Bechor, S.; Zolberg Relevy, N.; Harari, A.; Almog, T.; Kamari, Y.; Ben-Amotz, A.; Harats, D.; Shaish, A. 9-cis $\beta$-Carotene increased cholesterol efflux to HDL in macrophages. Nutrients 2016, 8, 435. [CrossRef] [PubMed]

8. Greenberger, S.; Harats, D.; Salameh, F.; Lubish, T.; Harari, A.; Trau, H.; Shaish, A. 9-cis-rich $\beta$-carotene powder of the alga Dunaliella reduces the severity of chronic plaque psoriasis: A randomized, double-blind, placebo-controlled clinical trial. J. Am. Coll. Nutr. 2012, 31, 320-326. [CrossRef] [PubMed]

9. Rotenstreich, Y.; Belkin, M.; Sadetzki, S.; Chetrit, A.; Ferman-Attar, G.; Sher, I.; Harari, A.; Shaish, A.; Harats, D. Treatment with 9-cis $\beta$-carotene-rich powder in patients with retinitis pigmentosa: A randomized crossover trial. JAMA Ophthalmol. 2013, 131, 985-992. [CrossRef] [PubMed]

10. Wang, X.D.; Krinsky, N.I.; Benotti, P.N.; Russell, R.M. Biosynthesis of 9-cis-retinoic acid from 9-cis-betacarotene in human intestinal mucosa in vitro. Arch. Biochem. Biophys. 1994, 313, 150-155. [CrossRef] [PubMed]

11. Khoo, H.-E.; Prasad, K.N.; Kong, K.-W.; Jiang, Y.; Ismail, A. Carotenoids and their isomers: Color pigments in fruits and vegetables. Molecules 2011, 16, 1710-1738. [CrossRef] [PubMed]

12. Raja, R.; Hemaiswarya, S.; Rengasamy, R. Exploitation of Dunaliella for $\beta$-carotene production. Appl. Microbiol. Biotechnol. 2007, 74, 517-523. [CrossRef] [PubMed]

13. Ho, S.-H.; Chan, M.-C.; Liu, C.-C.; Chen, C.-Y.; Lee, W.-L.; Lee, D.-J.; Chang, J.-S. Enhancing lutein productivity of an indigenous microalga Scenedesmus obliquus FSP-3 using light-related strategies. Bioresour. Technol. 2014, 152, 275-282. [CrossRef] [PubMed]

14. Jin, E.S.; Melis, A. Microalgal biotechnology: Carotenoid production by the green algae Dunaliella salina. Biotechnol. Bioprocess Eng. 2003, 8, 331-337. [CrossRef]

15. Tafreshi, A.H.; Shariati, M. Dunaliella biotechnology: Methods and applications. J. Appl. Microbiol. 2009, 107, 14-35. [CrossRef] [PubMed]

16. Fu, W.; Guðmundsson, Ó.; Paglia, G.; Herjólfsson, G.; Andrésson, Ó.S.; Palsson, B.Ø.; Brynjólfsson, S. Enhancement of carotenoid biosynthesis in the green microalga Dunaliella salina with light-emitting diodes and adaptive laboratory evolution. Appl. Microbiol. Biotechnol. 2013, 97, 2395-2403. [CrossRef] [PubMed]

17. Borowitzka, M.A.; Siva, C.J. The taxonomy of the genus Dunaliella (Chlorophyta, Dunaliellales) with emphasis on the marine and halophilic species. J. Appl. Phycol. 2007, 19, 567-590. [CrossRef] 
18. Xu, Y.; Ibrahim, I.M.; Harvey, P.J. The influence of photoperiod and light intensity on the growth and photosynthesis of Dunaliella salina (Chlorophyta) CCAP 19/30. Plant Physiol. Biochem. 2016, 106, 305-315. [CrossRef] [PubMed]

19. Borowitzka, M.A. Algal growth media and sources of cultures. In Microalgal Biotechnology; Borowitzka, M.A., Borowitzka, L.J., Eds.; Cambridge University Press: Cambridge, UK, 1988; pp. 456-465.

20. Strickland, J.; Parsons, T.R. A Practical Handbook of Seawater Analysis, 2nd ed.; Fisheries Research Board of Canada: Ottawa, Canada, 1972; pp. 185-190.

21. Porra, R.J.; Thompson, W.A.; Kriedemann, P.E. Determination of accurate extinction coefficients and simultaneous equations for assaying chlorophylls a and b extracted with four different solvents: Verification of the concentration of chlorophyll standards by atomic absorption spectroscopy. Biochim. Biophys. Acta Bioenerg. 1989, 975, 384-394. [CrossRef]

22. Brindley, C.; Acién, F.G.; Fernández Sevilla, J.M. The oxygen evolution methodology affects photosynthetic rate measurements of microalgae in well-defined light regimes. Biotechnol. Bioeng. 2010, 106, 228-237. [CrossRef] [PubMed]

23. Delieu, T.J.; Walker, D.A. Simultaneous measurement of oxygen evolution and chlorophyll fluorescence from leaf. Plant Physiol. 1983, 73, 534-541. [CrossRef] [PubMed]

24. Ben-Amotz, A. Effect of low temperature on the stereoisomer composition of $\beta$-carotene in the halotolerant alga Dunaliella Bardawil (Chlorophyta). J. Phycol. 1996, 32, 272-275. [CrossRef]

25. Melis, A. Photosystem-II damage and repair cycle in chloroplasts: What modulates the rate of photodamage? Trends Plant Sci. 1999, 4, 130-135. [CrossRef]

26. Shaish, A.; Avron, M.; Pick, U.; Ben-Amotz, A. Are active oxygen species involved in induction of $\beta$-carotene in Dunaliella bardawil? Planta 1993, 190, 363-368. [CrossRef]

27. Levin, G.; Mokady, S. Antioxidant activity of 9-cis compared to all-trans $\beta$-carotene in vitro. Free Radic. Biol. Med. 1994, 17, 77-82. [CrossRef]

28. Orset, S.C.; Young, A.J. Exposure to low irradiances favors the synthesis of 9-cis beta, beta-carotene in Dunaliella salina (Teod.). Plant Physiol. 2000, 122, 609-618. [CrossRef] [PubMed]

29. Davidi, L.; Levin, Y.; Ben-Dor, S.; Pick, U. Proteome analysis of cytoplasmatic and plastidic $\beta$-carotene lipid droplets in Dunaliella bardawil. Plant Physiol. 2015, 167, 60-79. [CrossRef] [PubMed]

30. Foster, K.W.; Smyth, R.D. Light Antennas in phototactic algae. Microbiol. Rev. 1980, 44, 572-630. [PubMed]

31. Eitzinger, N.; Wagner, V.; Weisheit, W.; Geimer, S.; Boness, D.; Kreimer, G.; Mittag, M. Proteomic analysis of a fraction with intact eyespots of Chlamydomonas reinhardtii and assignment of protein methylation. Front. Plant Sci. 2015, 6, 3389. [CrossRef] [PubMed]

32. Davidi, L.; Shimoni, E.; Khozin-Goldberg, I.; Zamir, A.; Pick, U. Origin of $\beta$-carotene-rich plastoglobuli in Dunaliella bardawil. Plant Physiol. 2014, 164, 2139-2156. [CrossRef] [PubMed]

33. Demmig-Adams, B.; Adams, W.W., III. The role of xanthophyll cycle carotenoids in the protection of photosynthesis. Trends Plant Sci. 1996, 1, 21-26. [CrossRef]

34. Jahns, P.; Holzwarth, A.R. The role of the xanthophyll cycle and of lutein in photoprotection of photosystem II. Biochim. Biophys. Acta Bioenerg. 2012, 1817, 182-193. [CrossRef] [PubMed]

35. Jin, E.; Yokthongwattana, K.; Polle, J.E.W.; Melis, A. Role of the reversible xanthophyll cycle in the photosystem II damage and repair cycle in Dunaliella salina. Plant Physiol. 2003, 132, 352-364. [CrossRef] [PubMed]

36. Erdman, J.W.; Smith, J.W.; Kuchan, M.J.; Mohn, E.S.; Johnson, E.J.; Rubakhin, S.S.; Wang, L.; Sweedler, J.V.; Neuringer, M. Lutein and brain function. Foods 2015, 4, 547-564. [CrossRef] [PubMed]

37. Yu, H.; Wark, L.; Ji, H.; Willard, L.; Jaing, Y.; Han, J.; He, H.; Ortiz, E.; Zhang, Y.; Medeiros, D.M.; Lin, D. Dietary wolfberry upregulates carotenoid metabolic genes and enhances mitochondrial biogenesis in the retina of db/db diabetic mice. Mol. Nutr. Food Res. 2013, 57, 1158-1169. [CrossRef] [PubMed]

38. Hoefnagel, M.H.N.; Atkin, O.K.; Wiskich, J.T. Interdependence between chloroplasts and mitochondria in the light and the dark. Biochim. Biophys. Acta Bioenerg. 1998, 1366, 235-255. [CrossRef]

39. Hansberg, W.; Aguirre, J. Hyperoxidant states cause microbial cell differentiation by cell isolation from dioxygen. J. Theor. Biol. 1990, 142, 201-221. [CrossRef]

40. Dall'Osto, L.; Lico, C.; Alric, J.; Giuliano, G.; Havaux, M.; Bassi, R. Lutein is needed for efficient chlorophyll triplet quenching in the major LHCII antenna complex of higher plants and effective photoprotection in vivo under strong light. BMC Plant Biol. 2006, 6, 32. [CrossRef] [PubMed] 
41. Fu, W.; Paglia, G.; Magnúsdóttir, M.; Steinarsdóttir, E.A.; Gudmundsson, S.; Palsson, B.Ø.; Andrésson, Ó.S.; Brynjólfsson, S. Effects of abiotic stressors on lutein production in the green microalga Dunaliella salina. Microb. Cell Fact. 2014, 13, 3. [CrossRef] [PubMed]

42. Lamers, P.P.; Janssen, M.; De Vos, R.C.H.; Bino, R.J.; Wijffels, R.H. Exploring and exploiting carotenoid accumulation in Dunaliella salina for cell-factory applications. Trends Biotechnol. 2008, 26, 631-638. [CrossRef] [PubMed]

43. Ben-Amotz, A.; Lers, A.; Avron, M. Stereoisomers of $\beta$-carotene and phytoene in the alga Dunaliella bardawil. Plant Physiol. 1988, 86, 1286-1291. [CrossRef] [PubMed]

44. Xu, Y.; Schroeder, D.; Harvey, P. Dunaliella sp. from hypersaline environments. Presented at the Algae Biorefineries for Europe, Brussels, Belgium, 17-18 October 2017; Algae Biorefineries for Europe Web site. Available online: https:/ /algaebiorefineryconference.eu/wp-content/uploads/2017/11/S16.pdf (accessed on 19 October 2017).

(C) 2018 by the authors. Licensee MDPI, Basel, Switzerland. This article is an open access article distributed under the terms and conditions of the Creative Commons Attribution (CC BY) license (http://creativecommons.org/licenses/by/4.0/). 